\title{
Discursos de agricultura urbana em São Paulo: FORMAÇÃO, PROFUSÃO E CAPTURA
}

Urban agriculture discourses in São Paulo: formation, profusion, and capture

\author{
Martin Jayo \\ University of São Paulo, Brasil \\ martin.jayo@usp.br \\ Eduardo de Lima Caldas \\ University of São Paulo, Brasil \\ eduardocaldas@usp.br
}

RESUMO: O artigo visa a chamar a atenção para algumas formas recentes de apropriação da pauta da agricultura urbana na cidade de São Paulo. Para tanto, mediante análise histórica desenvolvida por Caldas e Jayo (2019) para as práticas paulistanas de agricultura urbana, o intuito é caracterizar os diferentes discursos em defesa desta atividade que, historicamente, se fizeram presentes na cidade. A discussão permite observar que os discursos tradicionais da agricultura urbana têm sido capturados por alguns novos atores, dentre os quais parte do setor público, que se apropria do tema de forma oportunista, e o mercado imobiliário, que promove um simulacro de agricultura urbana como elemento de marketing.

PalaVras-chave: agricultura urbana, segurança alimentar, agenda política, captura, São Paulo.

ABSTRACT: The article aims to draw attention to some recent forms of appropriation of the urban agriculture agenda in the city of São Paulo. To do so, we take up Caldas and Jayo's (2019) historical analysis of the urban agriculture practices in São Paulo in an attempt to characterize the different discourses that have defended this long-standing activity in the city. This discussion reveals that traditional discourses of urban agriculture in São Paulo have been seized by new actors, including part of the public sector, which 
appropriates these practices opportunistically, and the real estate market, which promotes an imitation of urban agriculture as a marketing strategy.

KeYWoRDs: urban agriculture, food security, political agenda, capture, São Paulo.

RESUMEN: El artículo busca llamar la atención acerca de algunas formas recientes de apropiación de los modelos de agricultura urbana en la ciudad de São Paulo. Por ello, sirviéndonos del análisis histórico desarrollado por Caldas y Jayo (2019) para las prácticas paulistanas de agricultura urbana, hemos buscado caracterizar los diferentes discursos en defensa de dicha actividad y que han surgido históricamente en la ciudad. La discusión permite observar que los discursos tradicionales de agricultura urbana han sido capturados por algunos nuevos actores, entre los cuales, el sector público, que se apropia del tema de forma oportunista, y el mercado inmobiliario, que promueve un simulacro de agricultura urbana como elemento de márketing.

Palabras Clave: agricultura urbana, seguridad alimentaria, agenda política, captura, São Paulo.

RESUM: L'article pretén cridar l'atenció sobre algunes formes recents d'apropiació dels models d'agricultura urbana a la ciutat de São Paulo. Per això, servint-nos de l'anàlisi històrica desenvolupada per Caldas i Jayo (2019) per a les pràctiques de São Paulo d'agricultura urbana, hem buscat caracteritzar els diferents discursos en defensa d'aquesta activitat i que han sorgit històricament a la ciutat. La discussió permet observar que els discursos tradicionals d'agricultura urbana han sigut capturats per alguns nous actors, entre els quals, el sector públic, que s'apropia del tema de manera oportunista, i el mercat immobiliari, que promou un simulacre d'agricultura urbana com a element de màrqueting.

Paraules clau: agricultura urbana, seguretat alimentària, agenda política, captura, São Paulo. 


\section{Introdução}

Como já amplamente discutido, a agricultura urbana está longe de ser uma prática recente. Desde a antiguidade, há abundantes registros do cultivo sistemático de frutas, legumes e hortaliças em meio urbano para fins alimentares (Zaar, 2001; Nagib, 2016; Capel, 2002). Somente no século XIX, com o adensamento das cidades que se seguiu à Revolução Industrial, é que as práticas agrícolas desapareceram das cidades ocidentais, com a transferência da produção de alimentos para áreas externas, cada vez mais distantes (Navés, 2012).

A partir da década de 1970, no entanto, discursos em defesa da agricultura urbana começaram a tomar força em muitas cidades, introduzidos no debate público em tópicos como desenvolvimento sustentável, segurança alimentar e meio ambiente. Vista por muitos como uma novidade na agenda urbana, a proposta consiste, na verdade, em reintroduzir uma prática milenar caída em desuso nas cidades há relativamente pouco tempo.

As cidades brasileiras têm passado por processo semelhante. Com a acelerada urbanização que o país viveu no século xx, as grandes cidades perderam rapidamente seu tradicional cinturão verde ao mesmo tempo em que seu crescimento elevava a demanda por abastecimento. As áreas de produção tornaram-se cada vez mais distantes do consumo, impondo aumentos de custos logísticos, perdas de qualidade e desafios ambientais e de segurança alimentar (Caldas e Pinheiro, 2004). É nesse contexto que, a partir da década de 1980, o discurso da agricultura urbana foi trazido ao debate, ingressando na agenda de políticas públicas de diferentes cidades no país.

Este artigo pretende discutir os diferentes discursos em prol da agricultura urbana na cidade de São Paulo, da década de 1980 até a atualidade. Para tanto, será analisado o histórico da agricultura urbana paulistana desenvolvido por Caldas e Jayo (2019) para comparar as visões de agricultura predominantes em diferentes períodos. A escolha de São Paulo se justifica por ser a cidade brasileira que mais intensamente experimentou o processo de urbanização e adensamento acima mencionado, e também por ter sido, a partir da década de 1980, palco de uma variedade de políticas públicas governamentais e iniciativas da sociedade civil que construíram seus discursos sobre o tema. Com a análise, será possível observar como, na atualidade, os discursos mais tradicionais em defesa da agricultura urbana têm sido capturados por novos setores, entre os quais de parte do setor público e o mercado imobiliário.

Não é objetivo do artigo estender-se sobre definições conceituais de agricultura urbana, algo que já foi feito por Nahmias e Le Caro (2013), Oliveira (2017), Mougeot 
(1999), entre outros. Para a discussão empreendida aqui, é suficiente considerar, como definição de trabalho, que «agricultura urbana nada mais é do que o nome diz: produção de alimentos dentro da cidade. Em geral, caracteriza-se pela ocupação sistemática e ampliada de terrenos ociosos dentro do traçado urbano, com a implementação de hortas e pomares individuais, comunitários ou coletivos» (Caldas e Jayo, 2017). Ressalte-se que não está incluída nesta definição a agricultura praticada em espaços periurbanos, isto é, fora da mancha urbana, mas próximo dela. Em São Paulo, este tipo de agricultura é praticado na região de Parelheiros, no extremo sul do município, mas não é objeto de discussão principal neste artigo.

\section{Os discursos de agricultura urbana em São Paulo (1982-2019)}

A cidade de São Paulo, assim como outros centros urbanos no Brasil, perdeu ao longo do século Xx seu tradicional cinturão verde produtor de hortifrutigranjeiros. A periferia e o subúrbio adensaram-se, e áreas que outrora abrigavam chácaras produtoras tornaram-se bairros densamente povoados. A especulação imobiliária, o modelo espraiado de crescimento urbano e até mesmo as políticas públicas de habitação, dos antigos conjuntos habitacionais da $\mathrm{COHAB}$ ao mais recente programa Minha Casa Minha Vida, ${ }^{1}$ favoreceram esse processo.

Caldas e Jayo (2019) desenvolveram um histórico da agricultura urbana na cidade de São Paulo desde o surgimento de sua agenda no início da década de 1980 até a atualidade. Essa análise mostrou como as práticas oscilaram desde então entre duas modalidades de agricultura urbana: de um lado uma "agricultura urbana de escala", de outro uma "agricultura urbana de visibilidade". A proposta deste trabalho é retomar esse histórico, promovendo uma análise para caracterizar os discursos em defesa da agricultura urbana que se fizeram presentes em diferentes momentos, praticados pelo poder público e demais atores com interesse no tema.

Para tanto, cumpre destacar quatro momentos, compondo uma periodização: 19831987 (discurso da agricultura urbana como ação comunitária); 2001-2004 (discurso de agricultura urbana como política estatal), 2005-2016 (discursos mistos) e 2017 em diante (profusão dos discursos e agricultura urbana capturada).

1. A сонав (Companhia Metropolitana de Habitação de São Paulo) é uma empresa estatal criada em 1965 pela Prefeitura de São Paulo, responsável por executar políticas municipais de habitação. O Programa Minha Casa Minha Vida é um programa federal, lançado em 2009, voltado a subsidiar a aquisição de moradias próprias por famílias de baixa renda. Historicamente, ambos priorizam o investimento em unidades habitacionais nas áreas periféricas da cidade. Sobre as implicações disto para o ordenamento da cidade, ver, por exemplo, Saldiva (2018). 


\section{3-1987: o discurso da agricultura urbana como ação comunitária}

A gestão de André Franco Montoro no governo do Estado de São Paulo (1983-1987) foi uma importante incentivadora da agenda da agricultura urbana. Primeiro governador de São Paulo eleito por voto direto no contexto de redemocratização do país na década de 1980, Montoro teve uma gestão marcada pela promoção da descentralização administrativa. Fomentou a criação de conselhos de participação popular, entre outras medidas à época inovadoras, voltadas a fomentar o engajamento da comunidade organizada em políticas públicas e programas governamentais. Tais medidas eram resultado de pelo menos dois fatores: pelo lado da sociedade, a abertura política significava uma demanda por políticas democratizantes e socialmente transformadoras; pelo lado dos gestores do Estado, havia uma «nítida vontade de romper com sua estrutura centralizada e autoritária» (Porta, 1991, p. 52), valorizando-se a descentralização, a democratização do aparelho de Estado e a participação popular como diretrizes norteadoras.

As políticas de segurança alimentar e nutricional da gestão Montoro não foram exceção a essa regra. Até então, os principais programas governamentais nessa área eram centralizados pelo Governo Federal. Aos estados, cabia apenas a execução em nível local das decisões federais, tarefa que, ainda assim, esbarrava em dificuldades administrativas e orçamentárias (São Paulo, 1985). Em um contexto de crise econômica, aumento do desemprego e redução do nível de renda da população, o governo Montoro, «eleito diretamente e de orientação político-partidária distinta ao poder central, opta a partir de 1985, por desenvolver projetos de menor porte e viáveis quanto à execução» (Porta, 1991, p.51).

No bojo desses projetos, desenvolveu-se um conjunto de políticas denominado «Batalha da Alimentação» (São Paulo, 1987), sustentado por três diretrizes básicas: (i) incremento na produção de gêneros de primeira necessidade por meio de apoio ao pequeno e médio produtor (financiamento e seguro rural, assistência técnica, eletrificação rural, infraestrutura de estradas vicinais); (ii) incremento na produção de alimentos para o autoconsumo (hortas comunitárias, projetos em parceria com prefeituras e comunidades); e (iii) fomento a novas formas de comercialização e distribuição de alimentos (feiras do produtor, compras comunitárias). 
Coerente com essa proposta e no contexto de crise econômica do início da década de 1980, o Fundo Social de Solidariedade do Estado de São Paulo (entidade filantrópica oficial mantida pelo governo estadual) e a Secretaria de Agricultura e Abastecimento do governo estadual incentivaram a formação de hortas para amenizar os efeitos da recessão e do desemprego na mesa das famílias. Também foi envolvida nos esforços a Eletropaulo, companhia de transmissão de energia elétrica, à época uma estatal pertencente ao governo do Estado, que cedeu para cultivo terrenos de sua propriedade localizados sob linhas de transmissão. Um projeto-piloto foi lançado da Zona Leste da capital e, com sua repercussão positiva, a ideia foi aperfeiçoada, transformada em programa e difundida por todo o Estado (Montoro e Cavalcanti, 2000).

Quanto ao discurso predominante neste primeiro momento, observa-se que, embora as iniciativas fossem governamentais, sua lógica baseava-se no envolvimento e na participação da comunidade. Isso pode ser caracterizado pelos elementos lexicais predominantes na formulação, comunicação e implementação da política: não se tratava de o governo estadual afirmando que iria "fazer", "realizar" ou "implementar", mas sim de "apoio", "parceria", "fomento" - ou seja, construção e disponibilização de instrumentos a partir dos quais a comunidade organizada materializaria a política.

Em 1984, a Secretaria de Estado dos Negócios do Interior distribuiu um material institucional produzido pelo CEPAM - Fundação Prefeito Faria Lima, com a finalidade de apoiar os Programas Municipais de Alimentação. O material, com tiragem de 3 mil exemplares distribuídos em encontros municipais tinha por objetivo "incentivar a difusão de ideias que estão dando certo, buscando o envolvimento e mobilização de populações em todo o Estado" (CEPAM, 1984, p. 3, grifo nosso). O caráter comunitário do discurso era explicitado: o Estado diagnosticava o problema e propunha solução, mas esta dependia da "motivação" e da "resposta vigorosa" por parte das comunidades, de quem se esperava contribuição para o esforço para a consolidação da iniciativa:

Nas zonas urbanas, existe significativa quantidade de áreas fragmentadas e mesmo contíguas, sem nenhum funcionamento imediatamente produtivo. Os terrenos públicos e domésticos ociosos podem representar um importante fator de produção de alimentos. Por outro lado, também a ociosidade da mão 
de obra urbana, decorrente do desemprego e subemprego, é um fato evidente, constituindo outro fator estimulador de uma agricultura alternativa. O Governo do Estado, através de Agricultura e Abastecimento e da Secretaria do Interior, vem incentivando uma série de atividades agrícolas urbanas. A resposta tem sido vigorosa por parte das comunidades, que, motivadas, contribuem no esforço para a consolidação das iniciativas e seus desdobramentos. (CEPAM, 1984, p. 14)

De que forma as comunidades poderiam responder? Para apoiá-las, produziu-se um material didático, no escopo de um programa que se denominou «Horta e Criação Comunitária». O material e seus títulos ilustram uma vez mais o caráter comunitarista do discurso: a cartilha era organizada em seções com orientações voltadas a apoiar a mobilização: «Forme o grupo participante», «Escolha olocal», «Organize o trabalho», e assim por diante (figura 1).

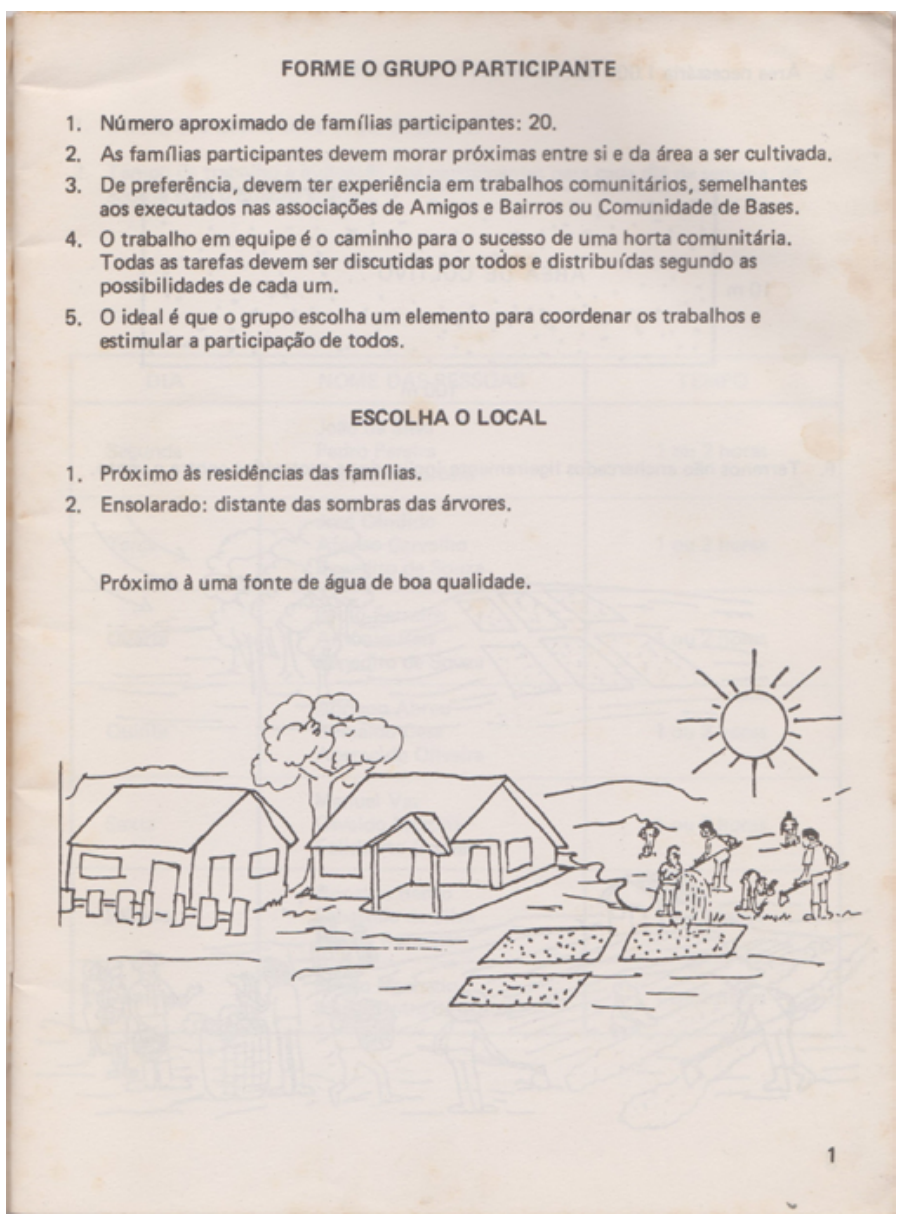

Figura 1. Exemplo do discurso comunitarista da década de 1980. Fonte: Reprodução de página interna da cartilha do Programa Horta e Ação Comunitária (1984). 
O discurso comunitarista aparece novamente na avaliação de resultados. Em 1987, o governo estadual considerou que «a população respondeu prontamente a essa proposta, que se tornou um sucesso graças à organização das comunidades, que possibilitaram sua estruturação em Programas de Governo, garantindo recursos financeiros, materiais e assistência técnica» (São Paulo, 1987, p. 100). Os resultados não são atribuídos diretamente à ação do Estado, embora este tenha cumprido um papel, mas à resposta social por meio de ação comunitária. Enquanto o Fundo Social de Solidariedade apoiava com recursos, «distribuindo mais de 2.000 ferramentas e 5.709 toneladas de compostos orgánicos» (São Paulo, 1987, p. 102), e a Secretaria de Agricultura e Abastecimento com assistência técnica e distribuição de sementes, era por meio da mobilização e da organização nas comunidades que a política tomava corpo e gerava resultados.

O reflexo desta mobilização foi o desenvolvimento, entre 1983 e 1986, de cerca de 248 mil hortas domiciliares, 4.700 hortas comunitárias e escolares em praticamente todas as cidades do estado de São Paulo, colaborando com a complementação alimentar de mais de 2 milhões de pessoas.

Um fato surpreendente é que, na Região Metropolitana de São Paulo, diversas dessas hortas são produtivas até hoje, como é o caso das vinculadas à Associação de Agricultores da Zona Leste, como veremos adiante. Eram hortas que Caldas e Jayo (2019) classificaram como "agricultura urbana de escala", isto é, capazes de produzir alimentos em volume suficiente para abastecer contingentes significativos de consumidores locais.

\section{I-2004: discurso de agricultura urbana como política estatal}

Um interregno de mais de uma década transcorreria, depois do final do governo Montoro, até que a agricultura urbana voltasse à agenda pública em cidades brasileiras. No início da primeira década de 2000, ela reaparece de maneira mais ou menos simultânea não só em São Paulo, mas também em outros centros, como Porto Alegre, Rio de Janeiro, Belo Horizonte, Curitiba e Campinas. À diferença do ocorrido na década de 1980, desta vez as iniciativas não se deram em nível estadual, mas nas esferas municipais, e os 
esforços não foram somente do Poder Executivo, mas, em certos casos mobilizaram, também o Legislativo.

Em Porto Alegre, por exemplo, um programa foi implementado pela Prefeitura por meio da Secretaria Municipal de Indústria e Comércio, a partir de 2003. Este programa não se pautava apenas por questões de segurança alimentar e nutricional, mas tinha uma preocupação socioambiental mais abrangente. Propunha a agricultura urbana visando ao aproveitamento de resíduo orgânico produzido na cidade como adubo e o uso de águas residuais para a irrigação. As ações eram completadas por medidas como a isenção do Imposto Predial e Territorial Urbano (IPTU) para áreas destinadas à produção, e a destinação de microcrédito a mulheres empreendedoras de hortas urbanas. Valorizava-se a centralidade do governo local como promotor e articulador desses diversos componentes da política: a Prefeitura não tinha um papel apenas fomentador, mas era a principal executora. Isso contrasta com o modelo adotado em São Paulo na década de 1980 e se manifesta novamente em escolhas lexicais, no material que documenta a política (Porto Alegre, 2003): fala-se agora em «políticas públicas municipais», ressaltando o papel central do poder público, e não mais em fomento, parceria, mobilização, fornecimento de instrumentos. Trata-se de um discurso de agricultura urbana que enfatiza fortemente seu componente de política estatal.

$\mathrm{Na}$ cidade de São Paulo, o ressurgimento da agenda da agricultura se deu no período 2001-2004, que corresponde à gestão de Marta Suplicy, então filiada ao Partido dos Trabalhadores (PT), à frente do Executivo municipal. Mas o esforço se deu principalmente no Legislativo: em janeiro de 2004, a Câmara Municipal aprovou o Projeto de Lei $n^{0}$ 234/2003, de iniciativa da vereadora Lucila Pizani Gonçalves, também do PT, transformando-o na Lei Municipal no 13.727/2004. Instituía-se assim o Programa de Agricultura Urbana e Periurbana do Município São Paulo (PROAURP), que tinha entre seus objetivos declarados «combater a fome», «incentivar a produção para o autoconsumo» e «reduzir o custo do acesso ao alimento para os consumidores de baixa renda» (Lei Municipal $n^{\circ} 13.727 / 2004$, art. $2^{\circ}$ ). A Lei ainda previa a realização pela Prefeitura de um levantamento de áreas públicas e um cadastramento de áreas privadas compatíveis com a agricultura urbana (artigos $3^{\circ}$ e $4^{\circ}$ ) e criaria incentivos fiscais aos proprietários destas últimas 
mediante redução do IPTU, o Imposto Predial e Territorial Urbano, podendo, não obstante, proceder à utilização compulsória de terrenos privados ociosos $\left(\operatorname{artigo} 4^{\circ}\right.$ ).

A implantação das hortas seria viabilizada por «convênios com entidades privadas que desempenhem serviços de utilidade pública para a implementação do programa» (Lei Municipal no 13.727/2004 art. 6º). Apesar disso, não há registro de quantidade expressiva desses convênios, nem de hortas produtivas que tenham resultado do programa à época. A promulgação da Lei foi seguida, é certo, da organização de alguns seminários e oficinas pelo Poder Público, porém estes eventos surtiram pouquíssimo efeito em termos de implantação efetiva de hortas. A própria regulamentação da Lei só se daria anos mais tarde, por meio do Decreto $n^{\circ} 51.801 / 2010$, já em outra administração.

Como se vê, os esforços em São Paulo se centraram na construção de um arcabouço legislativo que regulasse a agricultura urbana e fornecesse meios de ação ao Estado para incentivá-la, deixando de avançar, porém, rumo à efetiva mobilização da sociedade. As ações ficaram restritas ao âmbito do Estado, caracterizando um discurso de agricultura urbana como política estatal.

\section{5-20 I 6: discurso misto}

Entre 2005 e 2016, a agricultura permanece em evidência na agenda urbana sem que haja uma predominância de nenhum dos dois discursos anteriormente identificados. Tanto o discurso da agricultura urbana como ação comunitária, quanto o da agricultura urbana como política estatal, estão bem caracterizados. Daí a afirmação de que esta fase se caracteriza por um «discurso misto».

Em São Paulo, os primeiros oito anos desta fase (2005-2012) correspondem às gestões de José Serra, do Partido da Social Democracia Brasileira (PSDB), e Gilberto Kassab, do partido Democratas (DEM), na Prefeitura de São Paulo, e ao mesmo tempo à do médico sanitarista Eduardo Jorge Martins Alves Sobrinho, filiado ao Partido Verde (PV), na Secretaria Municipal do Verde e do Meio Ambiente. Por influência deste último personagem que, na fase anterior, também fora Secretário de Saúde na administração Suplicy, 
desenvolveram-se dois programas municipais que, embora não tivessem na agricultura urbana seu foco principal, incidiram sobre ela. O Programa Ambientes Verdes e Saudáveis (PAVS) e o Programa Parques Lineares propunham uma integração entre políticas de saúde, assistência social, ambiente e educação, até então pensadas e implementadas de forma compartimentada no município (Manhas, 2009).

O PAVS, viabilizado por meio de parceria entre a Secretaria Municipal do Verde e Meio Ambiente e a Secretaria Municipal da Saúde, consistia em capacitar agentes de saúde sensibilizando-os para a importância da interface entre meio ambiente e saúde. Atualmente, o Programa está vinculado à Secretaria da Saúde e tem mais de 1.500 projetos desenvolvidos simultaneamente, dentre os quais limpeza e manutenção de praças, formação e manutenção de hortas comunitárias e incentivo à alimentação saudável nas escolas. Já o Programa Parques Lineares consistiu na criação de parques em torno de rios e córregos recuperados pelo governo estadual. Vários destes parques foram parcialmente ocupados pela sociedade civil com a instalação autônoma de hortas, como é o caso da Horta das Corujas, às margens do córrego homônimo, na região da Vila Madalena, bairro de classe média na zona oeste de São Paulo.

Diversas hortas surgidas nesta época estão ativas até hoje, contribuindo para a recuperação de áreas abandonadas ou degradadas. Quanto ao discurso praticado em torno da agricultura urbana, elas estão, sem dúvida, mais próximas da concepção comunitarista da primeira fase (1983-1987) do que do discurso da agricultura urbana como política estatal que caracterizou a segunda (2001-2004). Por outro lado, há que se observar que as hortas resultantes jamais chegaram a produzir alimentos em escala significativa, configurando o que Caldas e Jayo (2019) chamaram de agricultura urbana "de visibilidade": ajudam a produzir consciência ambiental e chamam a atenção pública para a agenda política da agricultura urbana, mas sua contribuição é muito limitada em termos de produção efetiva de alimentos.

Ao mesmo tempo, e de forma independente desses programas, alguns produtores da Região Sul da capital paulista fortaleceram-se nesta época, na perspectiva de produzir em escala. Nesta vertente, estiveram presentes a Cooperativa Agroecológica dos Produtores Rurais de Água Limpa (COOPERAPAS), a Associação dos Agricultores Orgânicos (AAO) e a Associação 
de Pequenos Agricultores Familiares do Jardim Damasceno (APAFA). Esta modalidade de agricultura urbana «de escala» cresceria de forma significativa nos anos seguintes, chegando a abastecer diversas feiras e empórios (Couto e Pastre, 2018). Mais recentemente, em fevereiro de 2018, a COOPERAPAS firmou contrato com a Prefeitura da capital para o fornecimento de produtos orgânicos para a alimentação escolar no município (São Paulo, 2018). Pela primeira vez, alimentos orgânicos produzidos no próprio município passaram a ser servidos na merenda escolar da rede pública municipal. Isto assinala um progressivo ganho de importância da agricultura periurbana na agenda da cidade, para além da estritamente urbana. Porém, ainda que tenha contado com envolvimento de entidades da sociedade civil, como a COOPERAPAS e o Movimento Urbano de Agroecologia em São Paulo (MUDA-SP), esta política, como diagnosticaram Santos et al. (2019), baseou-se fortemente em instrumentos de autoridade, por meio dos quais o Poder Público fez prevalecer suas preferências, além de sua atuação como um ponto focal da política, disponibilizando informações e demais recursos de maneira centralizada para os demais participantes. Estas características aproximam, em boa medida, o discurso da política de uma concepção que enxerga a política de produção de alimentos como política governamental e a afastam do discurso comunitarista.

Por fim, no período de Fernando Haddad, do Partido dos Trabalhadores (PT), à frente da prefeitura de São Paulo (2013-2016), algumas medidas foram consolidadas na perspectiva de fortalecer a agricultura urbana, dentre as quais a promulgação da Lei 15.920/2013, que estabelece o Sistema Integrado Municipal de Segurança Alimentar e Nutricional, o estabelecimento de uma área rural para São Paulo e o reconhecimento da agricultura urbana e orgânica por meio da Lei 16.050/2014 (Plano Diretor Municipal). Aqui, a sociedade civil assumiu maior protagonismo com a ocupação de certos espaços públicos para constituição de hortas, destacando-se a Rede Hortelões Urbanos, o Movimento Urbano de Agroecologia de São Paulo (MUDA) e a Associação de Agricultores da Zona Leste. A Rede de Hortelões Urbanos fez intervenções que ganharam muita visibilidade, como foi o caso da Horta das Corujas, na região da Vila Madalena, que, embora tenha nascido no período anterior, ganhou grande repercussão midiática neste. Também ganhou fama a Horta do Ciclista, instalada em um pequeno canteiro em pleno leito da 
Avenida Paulista. São iniciativas mais próximas do discurso comunitarista. A grande visibilidade que alcançaram nesta época, no entanto, é inversamente proporcional à sua capacidade de produzir para alimentar pessoas. Nos termos de Caldas e Jayo (2019), não se trata de hortas «de escala», mas sim «de visibilidade», o que não diminui sua relevância se levarmos em conta que o ganho de visibilidade fortalece a ação para a construção de instrumentos que, por sua vez, favorecem a escala.

A Associação de Agricultores da Zona Leste (AAZL), por sua vez, originária das políticas iniciais do governo Montoro e ainda atuante, congregava 23 hortas em diversos bairros da zona leste da capital em 2018. Desde sua origem, muitas das áreas cultivadas por agricultores da AAZL situam-se como já mencionado em terrenos da companhia de transmissão de energia elétrica (atual AES Eletropaulo), mas também sobre adutoras de água Sabesp (empresa estadual de águas e saneamento) ou dutos da Braspetro (empresa estatal de petróleo), replicando modelo de parceria praticado desde a década de 1980 (Baron, 2017). São hortas que produzem agricultura urbana "de escala", remanescentes do comunitarismo dos anos 80 .

\section{8 em diante: agricultura urbana capturada?}

Se, nas diferentes fases desde a década de 1980, a agricultura urbana em São Paulo oscilou entre um discurso que ressaltava seu caráter comunitário e outro que a destacava como objeto de políticas governamentais de forma mais centralizada, na contemporaneidade parece observar-se uma profusão de discursos a respeito agricultura urbana. Diversas organizações, a exemplo do Serviço Social do Comércio (SESC-SP), voltaram suas atenções ao tema e passaram a promover atividades e programas voltados à agricultura urbana (SESC-SP, 2017). Universidades também se apropriaram do tema, destacando-se a Universidade Federal do ABC por meio do Núcleo de Estudos em Agroecologia e Produção Orgânica. Na Universidade de São Paulo, os destaques recaem sobre a Faculdade de Saúde Pública e a Faculdade de Medicina. Isto acabou por conferir ao tema uma evidência inédita: nunca se falou tanto em agricultura urbana, por meio de tantas vozes, como nos dois ou três últimos anos. 
Se por um lado isso pode ser visto como conquista dos movimentos ativistas, resultado de um lento processo de luta por visibilidade, por outro parece ser um fenômeno de captura discursiva da agricultura urbana por novos grupos de atores, sem interesse, ao menos direto, no debate. Até aqui havia dois discursos predominantes a respeito da agricultura urbana, um deles enxergando-a mais como atividade comunitária, outro privilegiando-a como objeto de políticas de Estado, surge agora uma profusão de novos discursos, alguns de caráter oportunista.

Um dos exemplos de captura vem de setores da própria Prefeitura (Palhares, 2017; Caldas e Jayo, 2017). Na administração João Doria Jr. (2017-2018), enquanto alguns agricultores da Zona Leste da cidade relatavam dificuldades com a perda de apoio do poder público municipal, a Prefeitura implantava o que se denominou «corredor verde»: uma área de 11 mil metros quadrados, plantada em canteiros verticais sobre muros da Avenida 23 de Maio, com mudas de alecrim, manjericão, orégano e salsa, entre outras espécies. Justificada como compensação ambiental pelo corte de 856 árvores em um empreendimento imobiliário na zona Sul da cidade, a iniciativa se apropriou do discurso em voga de agricultura urbana: à época da inauguração, chegou-se a propor que a população se utilizasse dos canteiros para abastecimento, colhendo ervas (Palhares, 2017). Embora se tratasse uma intervenção paisagística sem vínculo com a agricultura urbana, configura-se aí um exemplo de captura.

Um exemplo mais contundente vem do setor imobiliário. De um lado, há os shopping centers que implantam hortas sobre suas lajes de cobertura. Não se tem um mapeamento abrangente e completo dessas iniciativas e, tampouco, estudos sobre sua efetividade. Do ponto de vista discursivo, esses estabelecimentos passam se utilizar da agricultura urbana como elemento de construção de imagem: mais do que alimentos, estão interessados em cultivar a imagem de estabelecimentos preocupados com questões ambientais. $\mathrm{O}$ fluxo alimentar da cidade, o descarte de resíduos orgânicos e o uso eficiente de áreas desperdiçadas (os telhados e lajes) entram na agenda do marketing.

No entanto, ainda no setor imobiliário, incorporadoras de edifícios residenciais têm passado a incluir, nas áreas de uso comum dos empreendimentos, espaços para a instalação de hortas. Um dos primeiros a fazê-lo foi 
um edifício lançado em 2017 no bairro de Santa Cecília, região central da cidade. Em seu material promocional, vemos que os apartamentos têm proporções muito reduzidas (com áreas úteis com 10 metros quadrados), porém o edifício, quando concluído, contará com um extenso rol de equipamentos nas áreas comuns para o uso dos moradores. Em meio a itens habituais, como cozinha compartilhada, lavanderia coletiva, bicicletário, lojas de conveniência, academia de ginástica e «espaço gourmet», há planos para uma «horta compartilhada» (figura 2).
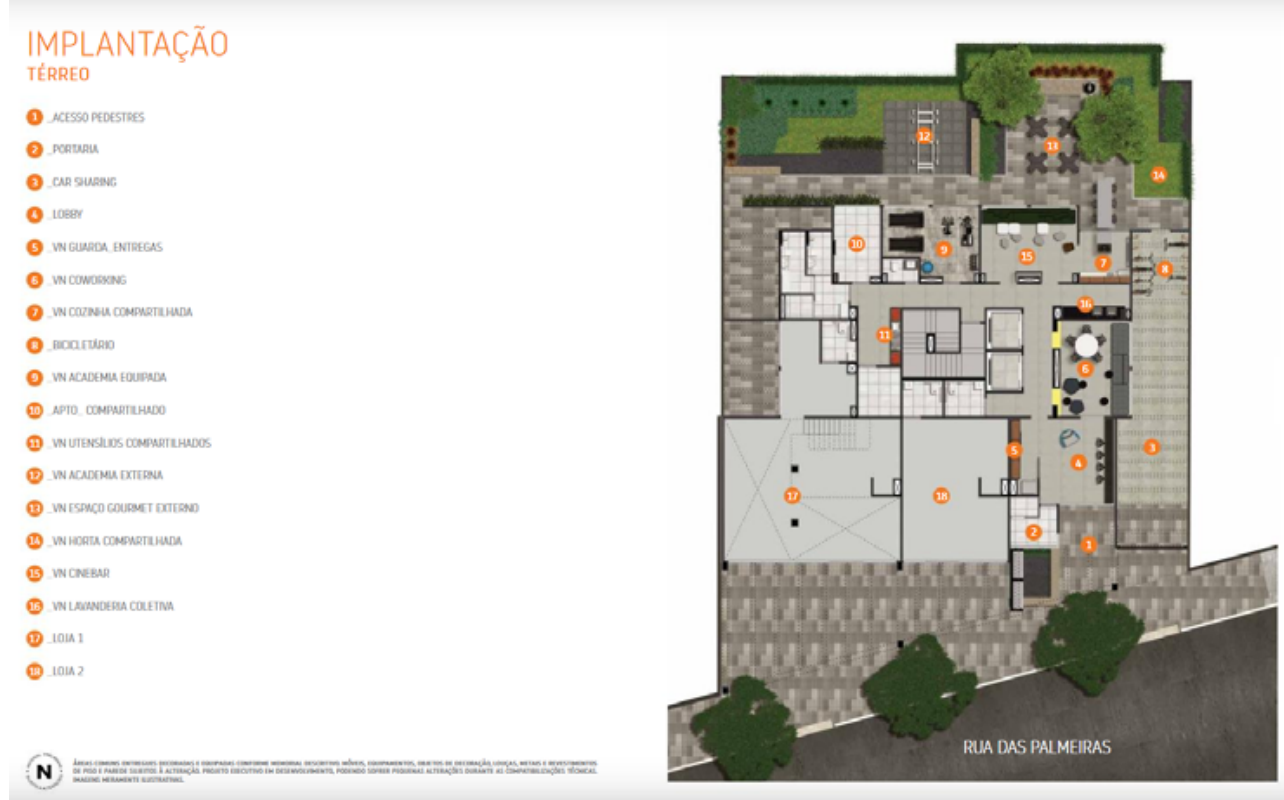

Figura 2. Material de divulgação de empreendimento imobiliário na região central de São Paulo. Fonte: imagem de divulgação reproduzida de https:// issuu.com/vitacon/docs/af_vit-0075-17_vitacon_campanha_nov (acesso em 24/04/2019).

Outro empreendimento, no bairro de Pinheiros, conta com uma detalhada imagem ilustrativa da futura horta em seu material de vendas (figura 3). No site da incorporadora, encontramos a seguinte descrição:

[...] o VN Capote Valente possui espaços pensados para socialização e bom relacionamento com outros moradores. Com espaço para coworking, bar na piscina e arquibancada com vista no $12^{\circ}$ andar, uma academia profissional equipada by Life Fitness, cozinha compartilhada para experiências gourmet, horta coletiva e muito mais. Escolha um novo estilo de vida que você possa aproveitar e curtir um pôr do sol com amigos, relaxar no spa, caminhar em um 
bosque de verdade no alto de um rooftop. Tenha novas experiências e reinvente sua vida urbana. ${ }^{2}$

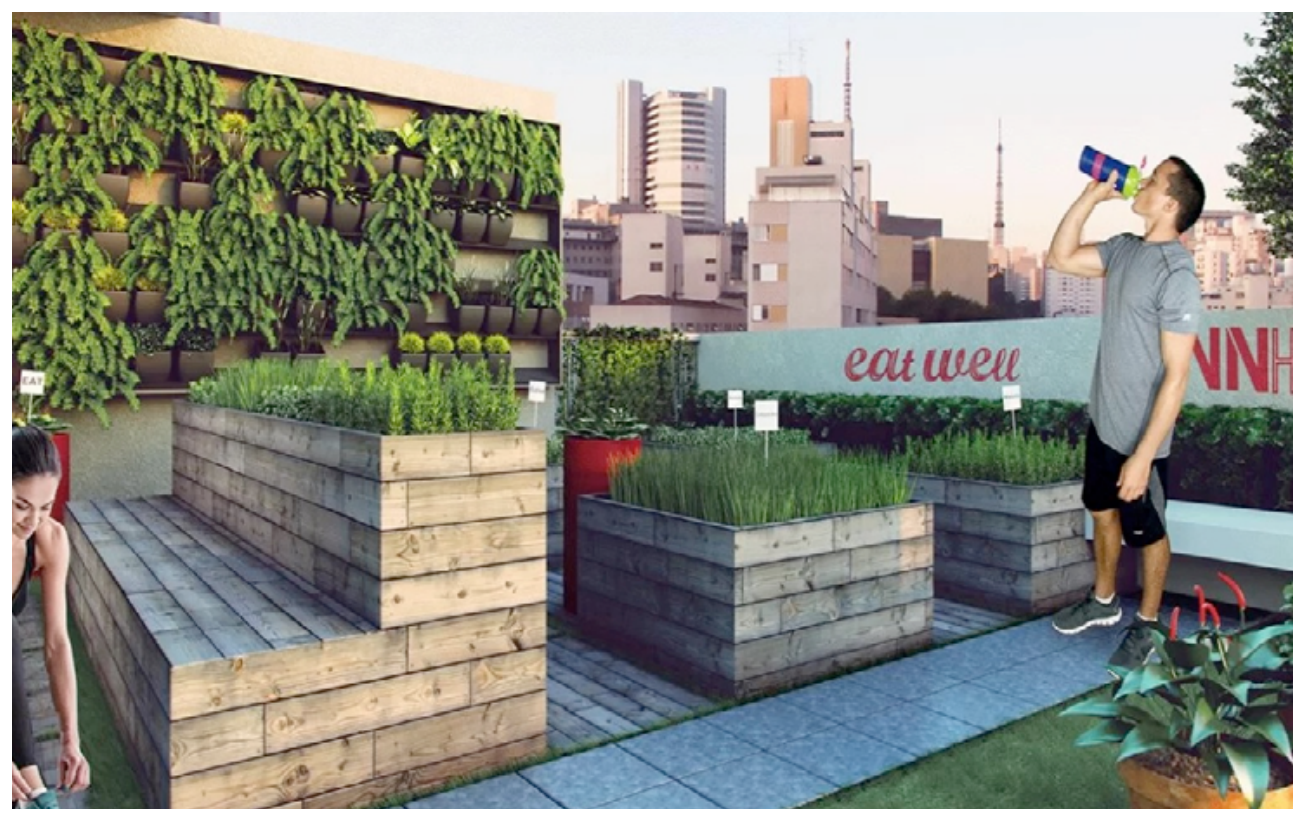

Figura 3. Material de divulgação de empreendimento imobiliário no bairro de Pinheiros. Fonte: imagem de divulgação reproduzida de https://www.coelhodafonseca.com.br/lancamento2-pinheiros-vn-capote-valente-900382181 (acesso em 24/04/2019).

Vale recordar que empreendimentos residenciais desta natureza, protegidos dos problemas urbanos por muros dentro dos quais oferecem aos moradores uma quantidade cada vez maior de itens de conveniência, consumo e lazer, promovem em boa medida a segregação e privatização de espaços de convivência e, por conseguinte, representam um desprezo pelo espaço público e por valores tradicionais da vida urbana, como a alteridade e a cidadania.

Neste sentido, a apropriação discursiva pelo mercado imobiliário parece representar um risco de esvaziamento da agricultura urbana, tornando-a um significante vazio, visto que cada um dos atores e setores que dela se apropria a insere em diferentes contextos, com valores e significados diferentes. Se, por mais de quatro décadas, o discurso da agricultura urbana em suas diferentes

2. Texto reproduzido de https://vitacon.com.br/blog/um-novo-estilo-de-viver-chegou (acesso em 24.04.2019). Grifo nosso. 
vertentes promoveu formas de integrar a cidade, pensar o fluxo alimentar, melhorar a morfologia urbana, diminuir o desperdício de terras e promover um modelo de desenvolvimento urbano mais sustentável, sua captura por estes novos atores sociais passa a promover um simulacro de agricultura urbana, esvaziada de seu sentido originário.

\section{Considerações finais}

Este trabalho certamente tem limitações, de forma que o que aqui se apresenta, mais do que como conclusões, deve ser lido como indicações para aprofundamento e continuidade da discussão. Um limite de nossa análise diz respeito à forma como apresentamos a evolução dos discursos de agricultura urbana, na forma de uma periodização em quatro fases: a do discurso «comunitarista» (1982-1987), a do discurso «estatal» (2001-2004), a dos discursos mistos (2005-2012) e a de profusão e captura (atual). Ao dividirmos o passado em fases tão bem delimitadas e homogêneas em seu interior, corremos risco de simplificação. A periodização, é sem dúvida, um recurso útil para representar processos históricos de mudança, porém cheio de armadilhas e sujeito a críticas por sempre envolver algum grau de reducionismo e arbítrio (Jayo, Rodrigues e Mendes, 2015).

Por outro lado, a discussão aqui empreendida, a nosso ver, contribui com o conhecimento disponível sobre a agricultura urbana paulistana, em particular ao chamar a atenção para algumas formas contemporâneas de apropriação, ou captura, da pauta da agricultura urbana. Complementando uma análise histórica desenvolvida em trabalho anterior (Caldas e Jayo, 2019), foi possível: (a) discutir os diferentes discursos em defesa da agricultura urbana que se desenvolveram na cidade de São Paulo, da década de 1980 até a atualidade, e (b) observar como os discursos tradicionais da agricultura urbana têm sido capturados por novos setores, dentre os quais parte do setor público, que se apropria do tema de forma oportunista visto que pouco o fez, se é que fez, recentemente para fortalecê-la como política, e o mercado imobiliário, que apresenta um simulacro de agricultura urbana em relação a suas concepções anteriores tornando-a peça de propaganda e instrumento de marketing de seus empreendimentos. 


\section{Referências}

Baron, Bernardo Chrispim (2017). Agroecologia e urbanidade: uma investigação a partir da agricultura urbana na Região Metropolitana de São Paulo. Trabalho de Graduação (Bacharelado em Geografia). Faculdade de Filosofia, Letras e Ciências Humanas da Universidade de São Paulo, São Paulo.

Caldas, Eduardo de Lima; Jayo, Martin (2019). Agriculturas urbanas em São Paulo: histórico e taxonomia. Confins, Paris, vol. 29. DOI: 10.4000/confins. 18639 .

Caldas, Eduardo de Lima; Jayo, Martin (2017). É pavê ou pacumê? Agricultura urbana em São Paulo em tempos de cidade linda. Minha Cidade, São Paulo, vol.18 n.205.

Caldas, Eduardo de Lima; Pinheiro, Edie (2004). Produzir alimentos na área urbana. Boletim Dicas n. 217. São Paulo: Instituto Pólis.

Capel, Horacio (2002). La morfología de las ciudades. Tomo I. Sociedad, cultura y paisaje urbano. Barcelona: Ediciones del Serbal.

CEPAM. Programas municipais de alimentação. São Paulo: Fundação Prefeito Faria Lima/Centro de Estudos e Pesquisas de Administração, 1984.

Couto, Cristiana; Pastre, Priscila (2018). Em alta, hortas urbanas comerciais começam a abastecer feiras e empórios de SP. Folha de S. Paulo, São Paulo, 27 jun.2018. <https://www1.folha.uol.com.br/ comida/2018/06/em-alta-hortas-urbanas-comerciais-comecam-a-abastecer-feiras-e-emporios-de-sp.shtml>, acesso em 23 set. 2018.

Jayo, Martin; Rodrigues, Andrea Leite; Mendes, Silma Ramos Coimbra (2015). "De oprimido a bon vivant: trajetória do administrador brasileiro segundo a publicidade". Revista Psicologia Política, São Paulo, v.15 n.34, p.617-645.Manhas, Cleomar Souza (2009). Programa Ambientes Verdes e Saudáveis: uma política pública popular integrada. Tempus. Actas em Saúde Coletiva, Brasília, v.4 n.4 p.121-134.

Montoro, André Franco; Cavalcanti, Pedro Rodrigues de Albuquerque (2000). Memórias em linha reta. São Paulo: Senac.

Mougeot, Luc J. A. (1999). "Urban agriculture: definition, presence, potentials and risks, and policy challenges". In: International Workshop on Growing Cities Growiong Food: Urban Agriculure on the Policy Agenda, Havana, 1999. < https://idl-bnc-idrc.dspacedirect.org/bitstream/handle/10625/26429/117785.pdf>, acesso em 20 set 2018 .

Nagib, Gustavo. Agricultura urbana como ativismo na cidade de São Paulo: 
o caso da Horta das Corujas. Dissertação (Mestrado Geografia Humana). Faculdade de Filosofia, Letras e Ciências Humanas da Universidade de São Paulo, São Paulo, 2016.

Nahmias, Paula; Le Caro, Yvon (2012). Pour une définition de l'agriculture urbaine: réciprocité fonctionelle et diversité des formes spatiales. Environnement Urbain, vol. 6, p. a1-a16.

Navés, Francesc (2012). Prólogo. In: Arosemena, Graciela. Agricultura urbana: espacios de cultivo para una ciudad sostenible. Barcelona: Editorial Gustavo Gili.

Oliveira, Lya Cynthia Porto de (2017). Redes, ideias e ação pública na agricultura urbana: São Paulo, Montreal e Toronto. Tese (Doutorado em Administração Pública e Governo), Escola de Administração de Empresas de São Paulo da Fundação Getulio Vargas.

Palhares, Isabela. 23 de Maio ganha $11 \mathrm{~km}$ de corredor verde. O Estado de S. Paulo, 05 ago. 2017, p. A-21.

Porta, Rogério Haucke (1991). Participação comunitária e ação do Estado: o abastecimento e a alimentação como bandeiras de luta - o caso da Organização Popular de Compras Comunitárias de Diadema/S.P. (1983-1988). Dissertação (Mestrado em Administração Pública). Escola de Administração de Empresas de São Paulo da Fundação Getulio Vargas, São Paulo.

Porto Alegre, Prefeitura do MunicíPio. Agricultura Urbana: orientações para a formulação de políticas municipais. Prefeitura Municipal de Porto Alegre, outubro de 2003.

Saldiva, Paulo (2018). Vida urbana e saúde: os desafios dos habitantes das metrópoles. São Paulo: Contexto.

São Paulo, Governo do Estado (1987). A Batalha da Alimentação no governo Montoro. São Paulo: PW.

- (1985). Avaliação da atuação governamental no setor de abastecimento. Governo do Estado de São Paulo, Secretaria da Agricultura e Abastecimento.

São Paulo, Prefeitura do Município (2018). Prefeitura incentiva agricultura familiar que fornece orgânicos para merenda escolar. Prefeitura do Município de São Paulo, Secretaria Especial de Comunicação, 23 mai. 2018. <http://www.capital.sp.gov.br/noticia/ prefeitura-incentiva-agricultura-familiar-que-fornece-organicos-para-merenda-escolar>, acesso em 20 set. 2018.

Santos, Fábio Baena dos; Caldas, Eduardo de Lima; Nonato, Raquel Sobal; Jayo, Martin. Introdução progressiva de alimentos orgâ- 
nicos e agroecológicos na merenda escolar no município de São Paulo: uma análise a partir dos instrumentos de ação pública. In: Anais do VIII Encontro de Administração Pública da ANPAD EnAPG 2019, Fortaleza, 2019.SESC-SP (2017). Ideias e ações para um novo tempo: territórios em transformação: mostra de iniciativas socioambientais 2017. São Paulo: Serviço Social do Comércio.

ZaAR, Miriam-Hermi (2011). "Agricultura urbana: algunas reflexiones sobre su origen e importancia actual”. Biblio 3W: Revista Bibliográfica de Geografia y Ciencias Sociales, Barcelona, vol. XVI n. 944. 